\title{
The Role of Library and Information Professionals in the Management of Indigenous Knowledge for the Attainment of Sustainable Entrepreneurial Development
}

\author{
Chinaka G. I. ${ }^{1}$, Iwuoha C. U. ${ }^{2}$, Abdullahi Z. M. ${ }^{3}$, Aniedu O. N. ${ }^{1}$ \\ ${ }^{1}$ College library, Federal College of Agriculture, Ishiagu Ebonyi State Nigeria \\ ${ }^{2}$ Research Library, National Root Crops Research Institute, Umudike, Abia State Nigeria \\ ${ }^{3}$ Modibbo Adama University of Technology, Yola, Adamawa State Nigeria
}

\section{Email address:}

chinakageorge@yahoo.com (Chinaka G. I.)

\section{To cite this article:}

Chinaka G. I., Iwuoha C. U., Abdullahi Z. M., Aniedu O. N.. The Role of Library and Information Professionals in the Management of Indigenous Knowledge for the Attainment of Sustainable Entrepreneurial Development. Science Journal of Business and Management. Special Issue: Sustainable Entrepreneurial Developments in Agribusiness. Vol. 3, No. 5-1, 2015, pp. 60-64. doi: 10.11648/j.sjbm.s.2015030501.23

\begin{abstract}
This article discusses the best practices in the management of indigenous knowledge for attainment of sustainable entrepreneurial development. Within this context, the following were reviewed: The definition of indigenous knowledge, types of indigenous knowledge and major areas of application of indigenous knowledge. Such areas as agriculture, ecosystem medicine, conflict resolution, traditional attire, weaving, carving, pottery, smiting, raffia work and bone-setting were examined. The papers also looked into management of indigenous knowledge. Critical areas of management includes: preservation, protection, documentation and restoration were examined. Some global initiatives on indigenous knowledge system were also reviewed. The roles of library and information scientist in the management of indigenous knowledge for the attainment of sustainable entrepreneurial development were covered.
\end{abstract}

Keywords: Information Professionals, Management, Indigenous Knowledge, Sustainable, Entrepreneurial Development

\section{Introduction}

Indigenous knowledge either in Africa or elsewhere is as old as man. It is unique to every culture and society. It is usually stored in people's memories, as folklores, monuments and practices (Religious or otherwise). According to [1] every society, whether simple or complex, has its own system of training and educating its populace. Education for good life has been one of the most persistent concerns of man throughout history. African education emphasizes social responsibility, job orientation, political participation and spiritual and moral values. Children learn by doing, that is children and adolescence are engaged in participatory education through initiation, ceremonies, rituals, invitation motivation and demonstration. They are involved in practical farming, fishing, weaving, cooking, currying knitting, drumming, acrobatic displays and racing. Intellectual training includes the study of local history, legends, story-relays etc. education in Africa was an integrated experience. prior to the coming western education to African indigenous knowledge played a vital role in agriculture, animal and human health, natural resources management, education and other vital economic and social activities [2] .

The United Nations Environment program (n.d) observed that documented literature on indigenous knowledge is limited Indigenous knowledge dealing with history and culture. Agricultural practices, health, local crafts/industry and recreation are usually passed from generation to generation through traditional socialization process and demonstration by elders and custodians. The reliability of this mode of dissemination is under threat in these modern times mainly due to the influx of western culture, higher levels of interactions between different communities, as well as the passing on of the custodians of this knowledge. Reacting to this observation, [4] suggested that unless indigenous knowledge is properly documented, analyzed and disseminated, it could be lost forever. This is where library and information professionals, who are well trained and properly equipped with skills in information and knowledge management becomes relevant.

The Objective of the study this paper therefore is intended 
to advance the need for proper identification, collection, analyzing, preserving, storing and dissemination of available information on indigenous knowledge for best practices and proper realization of sustainable entrepreneurial development.

\section{Indigenous Knowledge}

Edvinsson and Malone [3] in [4] wrote that knowledge can be interpreted in many ways depending on the context in which is used. A common definition of knowledge is the awareness and understanding of facts, truths and information gained in the form of experience or leaving. However, there are two kinds of knowledge the explicit knowledge which can be expressed in words and numbers and shared in the form of data, scientific formula, product, specifications, manuals, universal principles, and so forth. Tacit knowledge on the other hand is something not easily seen or visible and expressible.

Indigenous knowledge is predominantly a tacit knowledge passed from generation to generation, usually exchanged through personal communication (story telling is the most common way of transmitting, religious knowledge) culture rituals and demonstration. It is described as tacit, because it is stored in people's memories and activities and expressed in the form of stories and other cultural songs, Folklore, proverbs, dances, myths, cultural values, beliefs, rituals, community laws, local language and taxonomy, agricultural practices, equipment, materials, plant species, and animal breeds, which is shared and communicated orally [5]. Indigenous knowledge becomes explicit only, when it is translated or documented in any format.

\subsection{Global Initiatives on Indigenous Knowledge System}

The world is acknowledging that the concept of sustainable development can never be fully appreciated without integrating, indigenous knowledge in the development process. Some of the adduced reasons had been enumerated by [4]. Many initiatives on indigenous knowledge have been initiated at both global and African level to enlighten people around the world on various Indigenous knowledge activities and its use for sustainable development. In 2005, indigenous communities from 44 countries gathered at the community of commons, held at Fordham University, New York and made a proclamation otherwise known as community Declaration of 2005) and stated inter alia:

"We are calling upon the United Nations, its member states, multilateral organizations and other stakeholders to adopt the principle of the implementation of all MDGs and to empower local and indigenous communities also take control of their own development processes to ensure sustainability"

This was followed by five recommendations which were presented in [4] and extensively discussed to fulfill this proclamation.

\subsection{African Initiatives on Indigenous Knowledge}

A number of African initiatives have also been put in place on indigenous knowledge some of which are listed below:

- The North West University in South Africa established indigenous knowledge system learning, research and community programmes in 2001 at both undergraduate and postgraduate levels in the faculty of Human and Social Sciences. The rationale of these programmes is to level of abilities to work both critically and cooperatively in the promotion of indigenous knowledge and to sensitize them to the realities of indigenous knowledge system. The teaching curriculum and research activities are based on a multidisciplinary, historical and comparative approach.

- One other main objective of the programmes is to instill competencies among graduates and postgraduates to establish indigenous knowledge networks within and outside South Africa [6]. Also the South African National Research Foundation (NRF) is sponsoring 253 indigenous knowledge system projects at the cost of R30 million (NRF, n.d).

- The National Research Foundation (NRF) of South Africa publishes and indigenous knowledge system newsletter; to develop theoretical and methodological paradigms to understand indigenous knowledge system, shed light on the role of indigenous knowledge in nation building and develop research capacity in indigenous knowledge in South Africa (NRF, n.d.).

- The indigenous peoples of Africa coordinating. Committee (IPACC), is a network of indigenous peoples' organizations in Africa aimed at promoting recognition for indigenous peoples in Africa; strengthening leadership and organizational capacity of indigenous civil society in Africa; promoting tolerance and understanding of the cultural, spiritual and language diversity of Africa; and supporting sustainable economic development based on indigenous knowledge [7].

- Botswana is working on a project to explore how indigenous knowledge and Western scientific ideas can be used to control the AIDsf epidemic in the country [8].

- The African Ministerial council on science and Technology (AMCOST) was established in November, 2003. It is a free network to promote collaboration in science and technology in Africa. It also helps to consolidate science and technology programmes of the African Union (AU) Commission and the New Partnership for Africa's Development (NPAD) [9]. Its overall objective is to strengthen Africa capacity to harness and apply, as well as protect indigenous knowledge and technologies.

\subsection{Management of Indigenous Knowledge}

According to [4], oral tradition is the most important information gathering and sharing method in indigenous knowledge this way transmitted information inherited from past generations may be shared in both structured and unstructured contexts and tradition is categorized into five kinds: formula embedded, in slogans, ceremonial or spiritually derived language, poetry, leadership lists of 
reigning monarchs, narratives or toiles and commentaries. However, indigenous knowledge can be managed by: preservation, protection, documentation and restoration.

\section{Applications and Potentials of Indigenous Knowledge}

\subsection{Application of Indigenous Knowledge}

Major areas of application of indigenous knowledge by indigenous people communities are: agriculture, ecosystem medicine, conflict resolution, traditional attire, weaving carving pottery, smiting, raffia work, bone-setting etc.

- Agriculture: Indigenous knowledge (IK) facilitates agriculture, horticulture and forestry indigenous knowledge can determine favoured times and how to prepare, plant and harvest gardens, and farms, ways to propagate plants, seed storage and processing and crop planting. The can also suggest techniques of pest management and plant protection. Examples are using burnt cow dungs and neem (dogonyaro) seeds for preserving legumes and the use of manure as fertilizer with long residual content.

- Ecosystem medicine: Indigenous people have knowledge of the ecosystem's where they live and how to use natural resources sustainably. They use their indigenous knowledge for natural health, sustainable agriculture, and sustainable resource management [10]. In some African regions, knowledge of the local ecosystem is used as a means for survival. The ecosystem of many indigenous African countries reflects the traditional management practices, including individual and community wisdoms and skills in Indigenous soil taxonomies.

- Local knowledge of important tree species for agroforestry, firewood, integrated pest management, the control of soil erosion, and soil fertility and fodder management.

- Indigenous agronomic practices such as terracing, contour bounding, following, organic manure application, crop-rotation and multicropping.

- Indigenous soil and water conservation and anti-desertification practices [11].

- Medicine: [12] indicated that traditional medicine serves the heath needs of about $80 \%$ of people in developing countries, including Nigeria as orthodox medicine facilities are expensive and reasonably beyond affordable of common person. To maintain natural health, indigenous - knowledge provides traditional medicine and medical practices. Among the most popular African Traditional medical practices are: hydrotherapy, heal therapy, spinal manipulation, quarantine, bone-setting and surgery. Herbalists who practice traditional herbal medicine or have supernatural powers are believed to perform healing, embedded in beliefs of diverse cultures that ancestors' in the afterlife guide and protect the living [13].
- Conflict resolution: Traditional conflict resolution mechanisms in Africa are generally closely bound with socio-political and economic realities of the life styles of the communities. These mechanisms are rooted in the culture and history of the indigenous African community and are in one way or another unique to each community. In Nigeria, the use of Kolanut (Cola acuminate and Cola nitida) and the tender palm frond (Omu) are key instruments of peace negotiations and conflict resolution in Igbo community. Once a community gives these to another the receiving community is obligated to receive them in and also return similar gift. [14]. The customary courts rely on goodwill of the society to adhere to its rulings [15].

- Traditional attire: Traditional attire plays an important role in the identification of a particular culture. In Nigeria, agbada or babanringa, signifies the southwestern and northern tribe, Asho - oke, typical fabric for southwestern tribe, wrapper for all female attire in Nigeria [16].

\subsection{Benefits of Indigenous Knowledge System}

[4] Summarized the major benefits derivable from indigenous knowledge system as follows:

- Using indigenous knowledge in research gives such research legitimacy and credibility from researchers, and builds local capacity and empowerment.

- Indigenous people can provide valuable impute in the local environment for the efficient use and management of local resources.

- Indigenous knowledge is readily available at little or no cost.

- Through indigenous knowledge, African cultures are getting known better to the global society.

- In the endeavor to manage indigenous knowledge some of the lost African traditions and information are being rediscovered.

- Indigenous knowledge is vital for ecologically sensitive socio-economic activities.

- Indigenous knowledge can contribute to sustainable local and National development.

- Indigenous knowledge contributes to economic development this is evidenced by the explosion of herbal product into the global market.

\subsection{Constraints of Indigenous Knowledge System}

Poor entrepreneurial education: Entrepreneurship education is the process of inculcating the knowledge of creating value by pulling together a unique package of resources to exploit opportunity. Entrepreneurship education in institutions of higher learning is expected to help undergraduates at the end of their programme to be self employed, create jobs for others and play active role in the economic development Nigeria. The need to mitigate the hydra headed unemployment situation in the country and fast tract economic and industrial development of the country has made the teaching of 
entrepreneurship to undergraduates imperative.

Poor information management: Information is indispensable in the attainment of any goal set by a government or organizations. Library and information scientists are required to promote best practices in indigenous knowledge for sustainable entrepreneurial development by properly documenting analyzing and disseminating best practices in indigenous knowledge.

Poor policy enlightenment and dissemination: Information is highly indispensable in attainment of entrepreneurial development in order to mitigate the hydra headed unemployment problem of our teeming graduates in the recent past. Librarians and Information practitioners are better skilled to help in awareness creation and successful integration of indigenous knowledge practices and activities of the indigenous people in our country into the development process.

Initially the initiative will focus on awareness building, among decision makers in development organizations, and the national government. Librarians and information scientists could promote approaches to increase rural people's awareness of the wealth they posses and help them to further enrich it.

Report on indigenous practices in various fields should be collected and summarized in a publicly accessible database that also connects to the original source of information wherever possible. Cases could be published in a monthly periodical. International databases that responsibly make accessible all information that has been documented could effectively serve to educate and guide policy makers towards more appropriate and sustainable development solutions. In Nigeria for instance, The Akwete weaving industry, in Akwete Abia State, pottery industry in Ishiagu, Ebonyi State and Otta, Ogun State, bone-setting homes in Ishiagu, Ebonyi State; Umudimiobi, Ofekata, Orodo, Mbaitoli LGA in Imo State, and in Ikwuano LGA, Ohafia and Isiala - Ngwa in Abia State among several other knowledge-based arts are rapidly dying out for poor attentions and neglect.

As countries establish connectivity, modern ICT could become a powerful enabler for the exchange of information on indigenous activities and practices. External support to help build local capacity for dissemination could focus on videos, and radio broadcasts in local languages, tele-centers, and electronic networking, especially among local indigenous cultures, it also creates ample opportunities for illicit access to and misuse of traditional knowledge. Dissemination of indigenous practices could lead to the disempowerment of indigenous people. To protect the intellectual property rights of the indigenous people, librarians could, without compromising the principle of global knowledge partnership centre that royalties are paid before users are allowed to access to databases.

\subsection{The Role of Library and Information Professionals}

Library and Information scientists has critical roles in management of indigenous knowledge for the attainment of sustainable entrepreneurial development. According to [18] in [19] library and information scientists operates in three environments: - the organizational environment, the transactional environment and the contextual environment. These three environments are expected to control and monitor developments (both old and new) and determine best management options to achieve the desired goals and objectives [19]. Library and information scientist have articulated various activities and initiatives put in place for best practices in indigenous knowledge system. It is reasoned that if these initiatives and activities are harnessed and funded the problems of sustainable entrepreneurial development will highly be mitigated. Librarians should therefore apply information technology security mechanisms to be able to define and control the rights and access to their resources in order to uphold traditional laws; prevent the misuse of indigenous heritage.

Library and Information scientist, like the entrepreneur is someone who, through creativity innovation, foresight and discovery, can identify commercial opportunities around him or her while entrepreneurship is the process of creating something new with value by devoting necessary time and effort, assuming the accompanying, financial psychic and social risks, and receiving the resulting rewards of monetary and personal satisfaction and independence [17].

Entrepreneurship involves four major roles and aspects which include; (a) creating something new and/or of value to both the entrepreneur and the audience (customers) for which the product or service was developed. (b) devotion of necessary time and effort to create something new and make it operational. (c) rewards which include independence, personal satisfaction and huge profit (money reward) from the risks taken. Finally, entrepreneurship is uncertainty about actions taken. This is the reason why the entrepreneur takes calculated risks through preparation of business plan, feasibility study, which is a road map or a guide that facilitate achievement of their set objectives. This is the reason for their assertion that entrepreneurs are innovators and risk taker.

\section{Conclusion}

There are many untapped indigenous knowledge systems and activities in Nigeria that is not yet documented. The Federal, State and Local Government should formulate and strengthen policies setting up agencies or commissions whose sole responsibility will be to hunt for, identify and tap these resources so that sustainable entrepreneurial development using indigenous knowledge system could be developed.

\section{References}

[1] Fatunwa, A. B. (1996) History of Education in Nigeria. Revised education, Ibadan: NPS Educational Publishers' ltd. P. 349.

[2] Camble, Emmanuel and Aliyu, Yahaya (2008) indigenous knowledge in Nigeria; a case study of Soye community in Bana LGA, Borno State, Nigeria: libraries without Borders; Globalization of library and information services. In: Proceedings of the $4^{\text {th }}$ Annual Conference/AGM of Nigerian, Library Association pp. 41-49. 
[3] Edvinsson, I. and Malone, M. S. (1997) intellectual capital; realizing your company's true value by finding its hidden brainpower. Harper business, New York, pp10-15. $\mathrm{http}: / /$ www.gdre.org/kmgmt/km-7htm Ethiopia- conservation and sustainable use of medicinal plants project, (2001) Ethiopia-conservation and sustainable use of medicinal plant> project. http://go:worldbank.org/iLNUAGBM\&O.

[4] Jain, P. (2008) Indigenous Knowledge system in Africa. M.L.O. Aina, S.M. Mutula and M.A. Thamiyu (Eds.). Information and knowledge management in the Digital Age. Concepts, technologies and Africa perspectives, Ibadan: Third World Information Services Ltd. Pp. 300 - 331 .

[5] Chargulu A. S. (n.d.) Dissemination of Indigenous knowledge: 4 way to sustainable Agriculture. http://www.mangergov.in/managelib/faculty/cbary.httm. Accessed June 2012.

[6] Indigenous learning company (2007) ILC GOES to South Africa. http://www.indigenouslearning.com/news/articles/southafrica.

[7] IPACC (The Indigenous Peoples' of Africa Coordinating Committee (2007). Available at: http://www.ipacc.org.za/eng/default.asp.

[8] Nakaar, I (2005) The Role of Indigenous Knowledge system in Botswana.

http://depontments.oxy.edu/urc/urc-manual.old_urc/projects/th e_projects/public/2003projects/03biologyN.htm.

[9] AMCOST (2006) The African Ministerial Council on Science on Technology) securing and using Africa's indigenous knowledge base. http://www.nepadst.org/platforms/ik.shtml.

[10] Gough, A. (n.d.) Module for Indigenous Knowledge for environment based on Draft module by Annette Gough and Trials in Indonesia, Fiji, Brunel and Australia. http://www.ens.guiedu.au/au/cirec/LSE/MOD5.htm.

[11] Latonde, A. (n.d.) African Indigenous Knowledge and it's relevance to sustainable $\quad$ Development.
http://www.idro.ca/en/er-84408-201-1-DO.TOPIC.html.

12] WHO (2002-2005) WHO Traditional Strategy. http://wbqlibdoc.who.int/ag2002/WHO-EDM-TRM-2002.I.pdf.

[13] Isilow, H. (2007) Uganda: most foreign sangoma's in SA, are Ugandans, available http://allafrica.com/stories/stories/200704300377.html.

[14] Chimaraoke, O. F. (2002) Participatory Communal Conflict Resolution (PCCR) - A Take of two Nigerian Local Communities. PLA Notes, 43:61-63. Available at http://www.iied.org/NR/agbio/iv/pla-notes/documents/plan043 19.pfd.

[15] Edossa, D.C. (2005) Indigenous systems of conflict resolution in Oromia, Ethiopia. http://www.nri.org/waterlaw/awl.workshop/DESALEEN=CE. pdf.

[16] Kimani, M. (2004) Fashioning. Africa: power and the politics of Dress. http://www.feministafrica.org/05.2005/review-muttoni.htm.

[17] Anyanwu, E.U. et al (2012) integration of Entrepreneurship Education in Library and Information Science Curriculum in Nigeria. Nigerian Library Association $50^{\text {th }}$ National Conference and Annual General Meeting, “Abuja 2012" $15^{\text {th }}$ $19^{\text {th }}$ July, 2012.pp 224-233.

[18] Omekwu, O. O. (2003) Information professionalism in the Digital Age Cutting Edge Competencies in a competitive community, Lagos journal of Library and information science 1(2) Nov., 2003: 95-105.

[19] Okore, A. M. and Ekene, J. N. (2008) Information Professionals and knowledge management in Global Library and Information Services. Proceedings of the $46^{\text {th }}$ National Conference and Annual General Meeting of the Nigerian Library Association “KADUNA, 2008" 1-6 June, pp 55-61. 